\title{
Study on biology of mango mealy bug, Drosicha mangiferae (Green), (Tephritidae: Diptera)
}

\author{
Rajendra Singh $^{1 *}$, C.S. Prasad ${ }^{1}$, Deepak Kumar ${ }^{1}$, Hitendra Kumar ${ }^{2}$ and Neelam \\ Kumari $^{3}$ \\ ${ }^{1}$ Department of Entomology, S.V.P University of Agriculture \& Technology, Meerut, UP \\ ${ }^{2}$ Department of Entomology, SGRR (PG) College, Deharadun (Uttrakhand) \\ ${ }^{3}$ Department of Entomology, R.B. (P.G.) College Agra. \\ *Email: singhrajendra0113@gmail.com
}

\begin{abstract}
An experiment "study on biology of mango mealy bug, Drosicha mangiferae (Green), (Tephritidae: Diptera)" was conducted to the male and female incubation period lasted in ranged $81.20-300.67$ second. A single female bug laid around ranged 145 to 418 eggs which were oval in shape and their average length $\times$ width was $0.79-1.30 \mathrm{~mm} \mathrm{x}$ $0.412 \times 0.83 \mathrm{~mm}$. The nymphs were greenish in colour and the mean lengths of third instar nymphs ranged from 5.08-7.70 mm whereas; mean width ranged from 2.78 to $3.72 \mathrm{~mm}$ and the pupa was obtect type and 3.69 to $5.16 \mathrm{~mm}$ in length and $1.83-2.77 \mathrm{~mm}$ width. Adult female bugs are white in colour, elliptical in shape and body is covered with numerous minute hairs. Female bug were 12.12 to $18.53 \mathrm{~mm}$ in length and width were 17.12 to $18.53 \mathrm{~mm}$, respectively. The longevity of female bug was 9.33 to 53.67 days while adult male bug was 4.33 to 7.0 days. The adult male was crimson coloured with brownish black fore wings. Hind wings were reduced to small-flattened halters. It was observed that the mean wing span of adult male was ranged from 2.52 to $4.15 \mathrm{~mm}$.

Key words: Biology, mealy bug, mango, Drosicha mangiferae

Paper cited: Singh, R., Prasad, C.S., Kumar, D., Kumar, H. and Kumari, N. (2015). Study on biology of mango mealy bug, Drosicha mangiferae (Green), (Tephritidae: Diptera). South Asian J. Food Technol. Environm. 1(2):170174.
\end{abstract}

Mango (Mangifera indica L.) is the king of fruits from tropical areas of the world and also is the most important fruit crop of India and it has been recognized as "National fruit of India" because of delicious taste. Mango is also used to make the processed products like candy, relishes, pickles, beverages and many more. It is used not only for its various medicinal properties but its leaves and inflorescence are also used for religious rites. India is the largest mango producing country in the world. All parts of the mango tree are attacked by different insect pests, leading to direct or indirect losses in fruit yield depending on their severity of attack, which affects the production drastically. More than 400 insect pests have been listed attacking this king fruit (Srivastava, 2000). Out of these, mango mealy bug, D. mangiferae (Green), is the most important sucking insect pest causing damage at various stages of mango. In order to work out the integrated pest management schedule, it is necessary to know about the biology and nature of damage of insect. The female bug lays eggs in the soil in many egg sacs. The nymphs hatch and crawl up to the tree top and suck the vital sap from tender parts including leaves, twigs and inflorescence resulting in poor fruit setting
(Chandra et al., 1989). It is essential to know the peak activity stage of nymphal period and crawling up of the nymphal population as it helps to develop and promote an ecologically suitable and environmentally compatible pest management strategy to prevent the economic losses.

\section{Materials and Methods}

The present investigation "study on the biology of mango mealy bug, Drosicha mangiferae (Green)" was carried out at Bio-control Laboratory of S.V.P. University of Agriculture \& Technology, Meerut (U.P), and India. In order to study the life history of mango mealy bug, adults were released in jar and fed with $10 \%$ sucrose solution. The fresh leaves and twigs were kept in $45 \times 35 \mathrm{~cm}$ glass jars and $10 \mathrm{ml}$ sucrose $(10 \%)$ was added. Adult male and female in 1: 5 ratios were kept in jar and mating behaviour was observed for one-week duration.

After mating the female bugs were collected and released in glass jars containing $6 \mathrm{~cm}$ thick moist sandy soil and oviposition behaviour of mealy bug was observed for two months. Thereafter, egg sacs were collected for observation. The ovisacs in the field soil were also collected by digging around the 
tree trunk up to a depth of $30 \mathrm{~cm}$. The change in egg colour was observed by opening five egg sacs with the help of needle and pointed forceps at 15 days interval till hatching started. Twenty fresh laid eggs were taken randomly from egg sacs and placed in glass slides for measurement under stereo-binocular microscope fitted with ocular micrometer.

The duration between oviposition and hatching was recorded as incubation period and observation were recorded at every $24 \mathrm{hr}$ interval. Twenty nymphs of first, second and third instars were preserved in $70 \%$ alcohol $+5 \%$ glycerine in separate vials and labelled proper. Width and length of twenty nymphs were measured with the help of stereobinocular microscope fitted with ocular micrometer. With a view to record the duration of nymphal period of different instars, twenty freshly hatched nymphs were taken and kept separately. Food was changed at 2 days interval. Duration of different instars was recorded.

Twenty fully matured female nymphs were kept separately in plastic vials with 3-cm thick dry soil at bottom up to the formation of pupal case and pupation behaviour was studied. The third instar nymphs were kept for pupation in glass jar $(35 \times 45$ $\mathrm{cm})$. Time intervals between the cessation of feeding by last instar nymphs and commencement of cocoon for pupation were recorded as pre-pupal period. Whereas, the time required after completion of pupal cocoon up to adult stage was recorded as pupal period. Mode of emergence of adults from 20 pupal cases was observed in laboratory by keeping pupae in glass jars. The measurement of wing span of adult mango mealy bug was done using scale in $\mathrm{mm}$ and presented in the results. The period from egg laying till the death of adults was recorded as total life span of the insect.

\section{Results and Discussion}

The observations were recorded on the change in population size each day up to the end of the generation. The mango mealy bug, $D$. mangiferae (Green) comes under the order Hemiptera, Family Margarodidae (Coccidae).

Table: 1 Incubation period, no. of eggs laid and measurement of eggs of mango mealy bug, D. mangiferae

\begin{tabular}{|c|c|c|c|c|}
\hline \multirow[t]{2}{*}{ S. No. } & \multirow{2}{*}{$\begin{array}{c}\begin{array}{c}\text { Mean incubation } \\
\text { period (sec.) }\end{array} \\
\text { Incubation period }\end{array}$} & \multirow[t]{2}{*}{$\begin{array}{l}\text { No. of eggs laid/ } \\
\text { female }\end{array}$} & \multicolumn{2}{|c|}{ Measurement of eggs } \\
\hline & & & Length (mm) & Width (mm) \\
\hline 1. & $253.00 \pm 16.26$ & $411.67 \pm 36.55$ & $1.10 \pm 0.12$ & $0.701 \pm 0.06$ \\
\hline 2. & $255.33 \pm 10.72$ & $406.67 \pm 78.60$ & $1.10 \pm 0.09$ & $0.786 \pm 0.04$ \\
\hline 3. & $239.67 \pm 0.33$ & $401.67 \pm 39.83$ & $0.94 \pm 0.06$ & $0.735 \pm 0.04$ \\
\hline 4. & $242.00 \pm 5.57$ & $287.67 \pm 87.78$ & $0.96 \pm 0.04$ & $0.695 \pm 0.02$ \\
\hline 5. & $170.33 \pm 85.17$ & $368.33 \pm 82.07$ & $0.98 \pm 0.09$ & $0.737 \pm 0.04$ \\
\hline 6. & $300.67 \pm 32.28$ & $234.33 \pm 78.05$ & $0.95 \pm 0.03$ & $0.728 \pm 0.04$ \\
\hline 7. & $268.67 \pm 2.97$ & $371.67 \pm 61.67$ & $1.20 \pm 0.01$ & $0.735 \pm 0.05$ \\
\hline 8. & $253.67 \pm 1.77$ & $348.67 \pm 5.81$ & $0.96 \pm 0.04$ & $0.577 \pm 0.02$ \\
\hline 9. & $250.00 \pm 10.59$ & $316.00 \pm 35.56$ & $1.30 \pm 0.11$ & $0.753 \pm 0.04$ \\
\hline 10. & $250.00 \pm 10.79$ & $313.33 \pm 105.3$ & $0.93 \pm 0.06$ & $0.830 \pm 0.04$ \\
\hline 11. & $179.67 \pm 89.84$ & $333.33 \pm 41.77$ & $0.89 \pm 0.04$ & $0.412 \pm 0.12$ \\
\hline 12. & $243.33 \pm 8.09$ & $145.00 \pm 72.58$ & $1.10 \pm 0.06$ & $0.537 \pm 0.11$ \\
\hline 13. & $81.20 \pm 80.90$ & $156.00 \pm 57.24$ & $1.01 \pm 0.03$ & $0.578 \pm 0.10$ \\
\hline 14. & $258.33 \pm 10.08$ & $390.00 \pm 40.00$ & $0.98 \pm 0.05$ & $0.663 \pm .0 .85$ \\
\hline 15. & $257.00 \pm 11.92$ & $291.33 \pm 83.65$ & $1.01 \pm 0.13$ & $0.780 \pm 0.12$ \\
\hline 16. & $221.67 \pm 10.92$ & $370.00 \pm 57.51$ & $0.79 \pm 0.25$ & $0.690 \pm 0.64$ \\
\hline 17. & $236.33 \pm 3.18$ & $270.00 \pm 137.48$ & $1.01 \pm 0.07$ & $0.608 \pm 0.16$ \\
\hline 18. & $237.33 \pm 6.33$ & $255.00 \pm 5.00$ & $0.96 \pm 0.05$ & $0.703 \pm 0.04$ \\
\hline 19. & $250.33 \pm 15.37$ & $418.33 \pm 34.44$ & $0.99 \pm 0.02$ & $0.435 \pm 0.23$ \\
\hline 20. & $250.33 \pm 15.37$ & $300.00 \pm 141.80$ & $0.88 \pm 0.08$ & $0.703 \pm 0.08$ \\
\hline Range & $281.2-300.67$ & $145.00-418.00$ & $19.58-0.77$ & $13.39-0.41$ \\
\hline $\mathrm{CD}$ at $5 \%$ & NS & NS & NS & NS \\
\hline $\mathrm{SE}(\mathrm{m}) \pm$ & 35.46 & $104.00-0.054$ & 0.091 & 0.085 \\
\hline
\end{tabular}


Table 2: Measurement of body size of nymph and pupa of mango mealy bug, $D$. mangiferae

\begin{tabular}{|c|c|c|c|c|c|c|c|c|}
\hline \multirow[t]{3}{*}{ S. No. } & \multicolumn{6}{|c|}{ Measurement of nymphs } & \multirow{2}{*}{\multicolumn{2}{|c|}{ Measurement of pupa }} \\
\hline & \multicolumn{3}{|c|}{ Mean length (mm) } & \multicolumn{3}{|c|}{ Mean width (mm) } & & \\
\hline & $\mathbf{I}$ & II & III & I & II & III & $\begin{array}{l}\text { Mean length } \\
(\mathrm{mm})\end{array}$ & $\begin{array}{l}\text { Mean width } \\
(\mathrm{mm})\end{array}$ \\
\hline 1. & $2.117 \pm 0.613$ & $3.80 \pm 0.33$ & $7.65 \pm 0.44$ & $1.05 \pm 0.13$ & $2.26 \pm 0.30$ & $3.28 \pm 0.43$ & $4.64 \pm 0.42$ & $2.13 \pm 0.22$ \\
\hline 2. & $2.143 \pm 0.598$ & $4.23 \pm 0.17$ & $5.16 \pm 1.00$ & $0.49 \pm 0.28$ & $2.24 \pm 0.15$ & $2.78 \pm 0.12$ & $5.16 \pm 0.38$ & $2.48 \pm 0.37$ \\
\hline 3. & $2.573 \pm 0.297$ & $3.83 \pm 0.52$ & $5.92 \pm 1.15$ & $0.91 \pm 0.016$ & $2.44 \pm 0.32$ & $3.15 \pm 0.30$ & $4.70 \pm 0.11$ & $2.54 \pm 0.30$ \\
\hline 4. & $1.760 \pm 0.819$ & $3.57 \pm 0.36$ & $6.69 \pm 0.87$ & $1.13 \pm 0.17$ & $2.24 \pm 0.48$ & $2.78 \pm 0.43$ & $4.72 \pm 0.17$ & $2.53 \pm 0.13$ \\
\hline 5. & $2.030 \pm 0.433$ & $3.88 \pm 0.32$ & $6.80 \pm 0.44$ & $0.74 \pm 0.40$ & $2.62 \pm 0.13$ & $3.06 \pm 0.40$ & $4.90 \pm 0.27$ & $2.14 \pm 0.29$ \\
\hline 6. & $2.283 \pm 0.274$ & $3.91 \pm 0.06$ & $5.44 \pm 0.54$ & $1.17 \pm 0.19$ & $2.67 \pm 0.09$ & $3.34 \pm 0.50$ & $4.37 \pm 0.27$ & $2.38 \pm 0.25$ \\
\hline 7. & $2.847 \pm 0.026$ & $3.79 \pm 0.45$ & $6.17 \pm 0.86$ & $1.21 \pm 0.21$ & $2.64 \pm 0.12$ & $2.93 \pm 0.39$ & $4.81 \pm 0.56$ & $2.22 \pm 0.42$ \\
\hline 8. & $2.187 \pm 0.312$ & $2.54 \pm 1.30$ & $6.98 \pm 0.32$ & $0.90 \pm 0.45$ & $1.43 \pm 0.73$ & $3.72 \pm 0.19$ & $4.81 \pm 0.53$ & $2.51 \pm 0.34$ \\
\hline 9. & $1.533 \pm 0.809$ & $3.83 \pm 0.37$ & $5.28 \pm 1.36$ & $1.53 \pm 0.32$ & $2.61 \pm 0.32$ & $3.62 \pm 0.24$ & $4.19 \pm 0.24$ & $2.14 \pm 0.28$ \\
\hline 10. & $2.667 \pm 0.133$ & $3.43 \pm 0.09$ & $6.75 \pm 0.47$ & $0.69 \pm 0.15$ & $2.53 \pm 0.29$ & $2.91 \pm 0.33$ & $4.59 \pm 0.07$ & $2.26 \pm 0.16$ \\
\hline 11. & $1.700 \pm 0.862$ & $4.10 \pm 0.23$ & $6.97 \pm 0.28$ & $1.03 \pm 0.17$ & $2.62 \pm 0.12$ & $2.88 \pm 0.21$ & $5.15 \pm 0.34$ & $2.27 \pm 0.20$ \\
\hline 12. & $2.200 \pm 0.180$ & $2.24 \pm 1.12$ & $7.50 \pm 0.08$ & $1.19 \pm 0.31$ & $3.07 \pm 0.17$ & $3.58 \pm 0.12$ & $4.21 \pm 0.38$ & $2.70 \pm 0.18$ \\
\hline 13. & $2.367 \pm 0.318$ & $4.04 \pm 0.16$ & $6.64 \pm 0.41$ & $1.00 \pm 0.47$ & $2.37 \pm 0.28$ & $3.50 \pm 0.45$ & $4.66 \pm 0.11$ & $2.49 \pm 0.38$ \\
\hline 14. & $2.427 \pm 0.240$ & $3.71 \pm 0.47$ & $6.46 \pm 0.76$ & $0.68 \pm 0.25$ & $1.87 \pm 0.29$ & $3.68 \pm 0.13$ & $4.97 \pm 0.56$ & $2.27 \pm 0.40$ \\
\hline 15. & $1.710 \pm 0.569$ & $3.89 \pm 0.28$ & $6.32 \pm 0.50$ & $1.07 \pm 0.16$ & $1.80 \pm 0.26$ & $3.58 \pm 0.34$ & $4.32 \pm 0.18$ & $2.35 \pm 0.22$ \\
\hline 16. & $1.610 \pm 0.849$ & $4.25 \pm 0.18$ & $6.46 \pm 0.75$ & $0.83 \pm 0.34$ & $2.50 \pm 0.27$ & $3.52 \pm 0.12$ & $4.42 \pm 0.30$ & $2.47 \pm 0.34$ \\
\hline 17. & $1.900 \pm 0.950$ & $4.11 \pm 0.26$ & $7.34 \pm 0.47$ & $0.88 \pm 0.07$ & $2.55 \pm 0.34$ & $3.71 \pm 0.08$ & $3.69 \pm 0.37$ & $1.83 \pm 0.39$ \\
\hline 18. & $2.003 \pm 0.448$ & $4.25 \pm 0.28$ & $5.08 \pm 0.54$ & $0.80 \pm 0.00$ & $2.87 \pm 0.04$ & $2.90 \pm 0.08$ & $4.26 \pm 0.34$ & $2.19 \pm 0.24$ \\
\hline 19. & $2.640 \pm 0.131$ & $4.25 \pm 0.38$ & $7.70 \pm 0.08$ & $1.05 \pm 0.16$ & $1.48 \pm 0.76$ & $3.09 \pm 0.50$ & $4.53 \pm 0.33$ & $2.43 \pm 0.37$ \\
\hline 20. & $2.527 \pm 0.177$ & $4.00 \pm 0.18$ & $7.44 \pm 0.32$ & $1.04 \pm 0.13$ & $2.54 \pm 0.33$ & $3.61 \pm 0.23$ & $4.48 \pm 0.84$ & $2.77 \pm 0.13$ \\
\hline Ranged & $1.61-2.84$ & $2.24-4.25$ & $5.08-7.70$ & $0.49-1.21$ & $1.43-3.07$ & $2.78-3.72$ & $3.69-5.16$ & $1.83-2.77$ \\
\hline $\mathrm{CD}$ at $5 \%$ & NS & NS & N.S. & NS & NS & N.S. & NS & NS \\
\hline $\mathrm{SE}(\mathrm{m}) \pm$ & 0.54 & 0.482 & 0.869 & 0.26 & 0.341 & 0.312 & 0.382 & 0.294 \\
\hline
\end{tabular}


Table 3. Measurement of length, width and longevity of adult mango mealy bug, $D$. mangiferae.

\begin{tabular}{|c|c|c|c|c|c|c|c|c|}
\hline \multirow[t]{2}{*}{ S. No } & \multicolumn{2}{|c|}{ Mean length (mm) } & \multicolumn{2}{|c|}{ Mean width (mm) } & \multicolumn{2}{|c|}{$\begin{array}{c}\text { Mean wing span } \\
(\mathrm{mm})\end{array}$} & \multicolumn{2}{|c|}{$\begin{array}{c}\text { Longevity of adult } \\
\text { (days) }\end{array}$} \\
\hline & Male & Female & Male & Female & Male & Female & Male & Female \\
\hline 1. & $4.25 \pm 0.56$ & $15.80 \pm 1.28$ & $2.12 \pm 0.40$ & $7.56 \pm 0.66$ & $4.00 \pm 0.50$ & -- & $6.33 \pm 0.88$ & $20.67 \pm 3.84$ \\
\hline 2. & $4.68 \pm 0.56$ & $14.66 \pm 0.52$ & $1.92 \pm 0.58$ & $6.50 \pm 0.06$ & $3.36 \pm 0.33$ & -- & $5.17 \pm 0.60$ & $30.00 \pm 8.96$ \\
\hline 3. & $5.05 \pm 0.40$ & $16.85 \pm 0.25$ & $1.71 \pm 0.08$ & $7.15 \pm 0.26$ & $3.40 \pm 0.23$ & -- & $4.33 \pm 0.33$ & $25.67 \pm 2.19$ \\
\hline 4. & $4.67 \pm 0.47$ & $13.93 \pm 2.42$ & $1.14 \pm 0.23$ & $6.37 \pm 0.11$ & $3.73 \pm 0.62$ & -- & $5.33 \pm 0.73$ & $26.00 \pm 1.16$ \\
\hline 5. & $4.92 \pm 0.47$ & $14.85 \pm 0.60$ & $2.51 \pm 0.30$ & $8.50 \pm 0.29$ & $3.37 \pm 0.54$ & -- & $5.67 \pm 0.33$ & $30.00 \pm 2.52$ \\
\hline 6. & $5.14 \pm 0.31$ & $16.78 \pm 0.84$ & $2.10 \pm 0.08$ & $6.75 \pm 0.26$ & $3.60 \pm 0.08$ & -- & $7.00 \pm 0.58$ & $35.67 \pm 1.20$ \\
\hline 7. & $5.07 \pm 0.36$ & $17.51 \pm 0.72$ & $1.88 \pm 0.09$ & $8.18 \pm 0.25$ & $3.65 \pm 0.25$ & -- & $5.33 \pm 0.33$ & $09.33 \pm 1.86$ \\
\hline 8. & $5.68 \pm 0.11$ & $17.47 \pm 0.96$ & $1.80 \pm 0.06$ & $7.33 \pm 0.70$ & $3.58 \pm 0.47$ & -- & $5.83 \pm 0.73$ & $22.00 \pm 2.08$ \\
\hline 9. & $4.93 \pm 0.37$ & $12.12 \pm 0.28$ & $2.07 \pm 0.35$ & $6.53 \pm 0.14$ & $3.27 \pm 0.67$ & -- & $6.67 \pm 0.67$ & $31.00 \pm 3.61$ \\
\hline 10 & $5.09 \pm 0.38$ & $14.08 \pm 1.68$ & $1.44 \pm 0.31$ & $8.33 \pm 0.10$ & $2.75 \pm 0.37$ & -- & $5.33 \pm 0.83$ & $42.00 \pm 1.53$ \\
\hline 11. & $4.65 \pm 0.74$ & $12.73 \pm 0.98$ & $1.82 \pm 0.06$ & $8.20 \pm 0.06$ & $2.87 \pm 0.47$ & -- & $5.00 \pm 0.58$ & $50.00 \pm 1.73$ \\
\hline 12. & $4.84 \pm 0.06$ & $12.38 \pm 2.30$ & $1.78 \pm 0.12$ & $6.45 \pm 0.23$ & $3.71 \pm 0.67$ & -- & $4.33 \pm 0.44$ & $53.67 \pm 1.20$ \\
\hline 13. & $4.62 \pm 0.10$ & $16.60 \pm 1.82$ & $1.59 \pm 0.15$ & $7.70 \pm 0.12$ & $3.31 \pm 0.58$ & -- & $6.00 \pm 1.00$ & $09.67 \pm 1.76$ \\
\hline 14 & $5.45 \pm 0.30$ & $14.35 \pm 0.29$ & $1.84 \pm 0.11$ & $8.49 \pm 0.13$ & $5.46 \pm 0.41$ & -- & $6.33 \pm 1.36$ & $47.00 \pm 4.00$ \\
\hline 15. & $5.47 \pm 0.44$ & $16.96 \pm 0.93$ & $1.84 \pm 0.14$ & $8.58 \pm 0.49$ & $2.52 \pm 0.21$ & -- & $4.33 \pm 0.17$ & $46.00 \pm 2.00$ \\
\hline 16 & $4.87 \pm 0.06$ & $16.66 \pm 0.19$ & $1.43 \pm 0.31$ & $8.55 \pm 0.10$ & $2.76 \pm 0.44$ & -- & $5.67 \pm 0.44$ & $26.33 \pm 1.00$ \\
\hline 17 & $5.02 \pm 0.39$ & $17.22 \pm 0.99$ & $1.82 \pm 0.07$ & $8.00 \pm 0.42$ & $3.67 \pm 0.43$ & -- & $5.00 \pm 0.76$ & $27.00 \pm 2.00$ \\
\hline 18 & $5.27 \pm 0.30$ & $17.33 \pm 1.67$ & $1.81 \pm 0.03$ & $8.64 \pm 0.15$ & $3.83 \pm 0.62$ & -- & $5.00 \pm 0.60$ & $34.00 \pm 0.58$ \\
\hline 19. & $4.81 \pm 0.04$ & $16.35 \pm 0.20$ & $1.83 \pm 0.06$ & $6.36 \pm 0.08$ & $3.02 \pm 0.36$ & -- & $4.33 \pm 0.88$ & $37.00 \pm 1.33$ \\
\hline 20 & $4.22 \pm 0.41$ & $18.53 \pm 0.03$ & $1.85 \pm 0.01$ & $8.54 \pm 0.24$ & $4.15 \pm 0.62$ & -- & $5.67 \pm 0.50$ & $12.67 \pm 2.03$ \\
\hline Range & $4.25-5.47$ & $12.12-18.53$ & $1.14-2.51$ & $6.36-8.64$ & $2.52-5.46$ & -- & $4.33-7.00$ & $9.33-3.67$ \\
\hline $\mathrm{CD}$ at $5 \%$ & NS & 3.278 & NS & 0.872 & NS & -- & 1.986 & 8.397 \\
\hline $\mathrm{SE}(\mathrm{m}) \pm$ & 0.387 & 1.143 & 0.229 & 0.304 & 0.560 & -- & 0.692 & 2.927 \\
\hline
\end{tabular}

The complete metamorphosis occur only in male's life cycle, which comprised of four developmental stages, viz. egg, nymph, pupa and adult, whereas in case of female, incomplete metamorphosis has been observed comprising three developmental stages, viz., egg, nymph, and adult.

The copulation period lasted minimum 31 sec and maximum $861 \mathrm{sec}$ (ranged $31-861 \mathrm{sec}$ ). These finding confirms the findings of Atwal et al., (1969), who reported that coitus continues for $15 \mathrm{sec}$ to 5 min. It was observed that female bugs laid eggs mostly underside of ground leaves and in soil at a depth of 161-649 $\mathrm{mm}$ and their mean deposition period of days ranged from 4.3-14.3 days (Table 1). Present report supports the findings of Rahman (1940) and Reddy (1968), who reported that egg deposits at a depth of about $600 \mathrm{~mm}$. Contrary to the present finding, Chopra (1925), who reported that eggs laid at about 25-50 mm depth in soil. Rahman and Latif (1944) observed that eggs were commonly deposited at a depth of 50-150 mm in soft sandy soil.

Egg and egg laying capacity: A single female bug laid eggs in soil ranged 145 to 418 (Table 2). Similar results were reported by Singh (1960); Srivastava (1973) who reported that a single female lay about 300-400 eggs.

Incubation period: The incubation period of eggs $D$. mangiferae was recorded at ranged from 281.2 300.67 days (Table 1). These findings are in close conformity with the findings of Srivastava (2000).

Shape and size: It was evident that the eggs were oval in shape, whose average length was $0.79-1.30$ $\mathrm{mm}$ and width $0.435-0.830 \mathrm{~mm}$ (Table 1). These finding are closely conformity with respect to length $0.9-1.1 \mathrm{~mm}$ and width 0.65 to $0.75 \mathrm{~mm}$ as reported by Rahman and Latif (1944). 


\section{Nymph}

First instar: The freshly emerged first instars nymphs were delicate, elliptical and pink in colour. The length of first instar nymph was recorded as range (1.53 to $2.84 \mathrm{~mm}$ ) whereas, range width was ( 0.49 to $1.53 \mathrm{~mm}$ ) (Table 2). The present findings are in close conformity with the findings of Rahman and Latif (1944), who reported that $1.31-2.23 \mathrm{~mm}$ length and $0.70-1.19 \mathrm{~mm}$ breadth of first instar nymphs of $D$. mangiferae.

Second instar: Body colour was dull, grey brown with black colour. The mean length of second instar nymphs ranged from 2.24 to $4.25 \mathrm{~mm}$ whereas mean width ranged from 1.43 to $3.07 \mathrm{~mm}$, respectively (Table 2). The above finding corroborate with the reports of Beasson (1941) who recorded body length of $4 \mathrm{~mm}$.

Third instar (male): The nymphs were greenish in colour and the mean lengths of third instar nymphs ranged from $5.08-7.70 \mathrm{~mm}$ whereas mean width ranged from $2.78-3.72 \mathrm{~mm}$, respectively (Table 2). The above findings are in close conformity with Rahman and Latif (1944) who reported that the body length varied from 4.55 to $7.7 \mathrm{~mm}$ and greatest breadth 2.5 to $3.7 \mathrm{~mm}$. The nymphal period was completed in 10-12 days; these findings are supported by Chandra et al., (1989).

Pupa: Prior to undergoing pupation, the third instar male nymph stopped feeding and underwent pupation. They started forming silken cocoon below $3-4 \mathrm{~cm}$ in the tree trunk or crevices or bark of the tree. The body wrinkled and movement suspended. Newly formed pupae were seen light cream in colour, which turned to dark brown. The pupa was obtect type. The mean length of pupa was ranged from 3.69 to $5.16 \mathrm{~mm}$ whereas mean width ranged from 1.83 to $2.77 \mathrm{~mm}$ respectively (Table 2 ). These finding are supporting to the findings of Srivastava (2000).

\section{Adult}

Male: It was observed that adult male bug was crimson colored with brownish black fore wings. Body shape was elongated. Hind wings were reduced to small-flattened halters. It was observed that the length and width of adults male was ranged from 4.25 to $5.68 \mathrm{~mm}$ while width was range from 1.14 to $2.51 \mathrm{~mm}$, respectively (Table 3). Rahman and Latif (1944) support the present finding. The wing span of adult male ranged from 2.52 to $5.46 \mathrm{~mm}$ (Table 3). The longevity of adult male ranged from 4.33 to 7.0 days was observed (Table 3 ).
Female: Adult female bugs are white in colour, elliptical in shape and body is covered with numerous minute hairs. It was evident that length of female bug ranged from 12.12 to $18.53 \mathrm{~mm}$ whereas, mean width ranged from 6.363 to $8.643 \mathrm{~mm}$, respectively. The female bug longevity ranged from 9.33 to 53.0 days (Table 3). Rahman and Latif (1944) and Chandra et al., (1989) support the present investigation on female bug lengths, width and live days.

\section{References}

1. Anonymous, (2008). The Hindu Survey of Indian (Agriculture). Chennai

2. Atwal, A.S., Bhatti, O.S. and Sandhu, G.S. (1969). Some observations of the ecology and control of mango mealy bug, Drosicha mangiferae (Green). J Res Punjab Agric Univ, Ludhiana 6: 107-114.

3. Beesan, C.F. (1941). The ecology and control of the forest insects of India and the neighboring countries. The Vasant Press, Dehradun, India. p. 1007

4. Chandra, A., Singh, K. M. and Bhatti, D. P. S. (1989). Egg laying behaviour of gravid females of mango mealy bug, Drosicha mangiferae Green is influenced by soil moisture regimes. Indian J Entomol. 51: 101104.

5. Chopra, R.L. (1925). Annual Report of Entomologist to Government of Punjab. Lyallpur for the year 1925-26. Report of Department of Agriculture Punjab 1: 67-125.

6. Rahman, K.A. and Latif, M. (1944). Description, bionomics and control of giant mealy bug Drosicha stebbingi Green (Homoptera: Coccoidae). Bull Entomol Res. 35: 197-209.

7. Rahman, K.A. (1940). Punjab Agriculture College Magazine. 7: 5-7.

8. Reddy, D.B. (1968). Plant protection in India. Allied Publisher, Calcutta. p. 454

9. Singh, L.B. (1960). The Mango. Inter science Publisher Inc., New York. p.438

10. Srivastava, A.S., Singh, Y.P., Pandey, R.C. and Awasthi, B.K. (1973). Bionomics and control of the mango mealy bug. World Crops. 25: 87-88.

11. Srivastava, R.P. (2000). Mango insect pests and their management. In: Mango cultivation. International Book Distribution Co., Lucknow. p.187-299. 